\title{
Consequences of the nanoporosity of cellulosic fibers on their streaming potential and their interactions with cationic polyelectrolytes
}

\author{
Martin A. Hubbe, ${ }^{1,}$ Orlando J. Rojas, ${ }^{1}$ Lucian A. Lucia, ${ }^{1}$ and Tae Min Jung ${ }^{2}$ \\ North Carolina State University, ${ }^{1}$ Department of Wood and Paper Science, Box 8005, \\ Raleigh, NC 27695-8005, USA; Hansol Paper Co.,Ltd., ${ }^{2}$ 481-8, Whachon-Ri, \\ Changhang-Up, Seochun-Kun, Choongnam, Korea; * Author for correspondence (e- \\ mail:hubbe@ncsu.edu)
}

Key words: Porosity, Cellulose, Polyelectrolytes, Adsorption, Streaming Potential

\begin{abstract}
Electrokinetic tests, based on the streaming potential method, were used to elucidate interactions between cationic polyelectrolytes and cellulosic fibers and to reveal aspects of fibers' nanoporosity. The fibrillated and nanoporous nature of bleached kraft fibers gave rise to time-dependent changes in streaming potential, following treatment of the wetted fibers with poly-diallyldimethylammonium chloride. Electrokinetic test results were consistent with an expected longer time required for higher-mass polyelectrolytes to diffuse into pore spaces, compared to lower-mass polyelectrolytes. Further evidence of the relative inability of polyelectrolyte molecules to diffuse in to the pores of cellulose was obtained by switching back and forth between high and low ionic strength conditions during repeated measurement of streaming potential, after the fibers had been treated with a moderate amount of cationic polymer. By changing the concentration of sodium sulfate it was possible to switch the sign of streaming potential repeatedly from positive to negative and back again. Such results imply that a continuous path for liquid flow exists either in a fibrillar layer or within the cell walls. The same concepts also helped to explain the dosages of high-charge cationic polymer needed to achieve maximum dewatering rates, as well as the results of retention experiments using positively and negatively charged microcrystalline cellulose particles.
\end{abstract}

\section{Introduction}

Though the nanoporous nature (Stone and Scallan 1968; Berthold and Salmén 1997; Andreasson et al. 2003) and electrokinetic properties (Herrington and Petzold 1992; Lloyd and Horne 1993; Bygrave and Englezos 1998; Wang and Hubbe 2002) of cellulosic fibers have been the subject of considerable study, less attention has been paid to ways in which fibers' porous nature affects their interactions with electrically charged macromolecules (Koethe and Scott 1993; Gruber et al. 1996; Alince and van de Ven 1997; Tatsumi and Yamauchi 1997; Wang and Hubbe 2002). The goal of the present work has been to demonstrate ways in which the presence of pores at the fiber surface can affect electrokinetic properties of fibers, depending on the amounts, molecular masses, and times of treatment with high-charge cationic polyelectrolytes. A second goal is to show how such measurements, when carried out under contrasting conditions of 
ionic strength, can be used to reveal the continuous nature of at least part of the pore network either within or near the surface of cellulosic fibers.

Stone and Scallan (1968) used a solute exclusion method to characterize the pore size distributions within sulfite pulp fibers immersed in aqueous solution. Neutral dextran molecules and macromolecules of well-defined sizes were added in defined quantities to mixtures of fibers and water, followed by precise quantification of the bulkphase dextran concentrations. Based on such measurements, the greatest contribution to pore volume within fiber cell walls appeared to be due to pores having widths at least in the range of about 2 to $20 \mathrm{~nm}$. Other studies showed that many pores in this size range can close semi-irreversibly in response to the drying of cellulosic fibers (Stone and Scallan 1966; de Ruvo and Htun 1983; Laivins and Scallan 1993; Maloney et al. 1998). Related information about the dimensions of pore spaces within fibers has been obtained by inverse size-exclusion chromatography (Berthold and Salmén 1997), gas adsorption (Falth and Sholz 1993), nuclear magnetic resonance (Li et al. 1993; Andreasson et al. 2003), and scanning electron microscopy (Alince 2002; Duchesne and Daniel 1999).

An inherent problem with the solute exclusion methods cited above is that even if the non-interacting polymer molecules are just small enough so that they ought to fit into a small pore, it is not realistic to expect that the polymer's concentration within the pore to equal its bulk concentration (Fleer et al 1993). By being confined within a small pore, a soluble macromolecule loses some degrees of conformational freedom, and this effect renders its presence in a small pore thermodynamically unfavorable, relative to the bulk. To shed further light on the issue, Alince and Van de Ven carried out studies in which the probe macromolecules were highly cationic, providing a driving force for adsorption within the pores of cellulosic fibers (Alince and Van de Ven 1997). Results of their experiments suggested pore sizes that were generally larger than those obtained with neutral dextrans. To carry this type of approach one step further, a study by Gruber et al. (1996) exposed fiber suspensions to a series of poly-diallyldimethylammonium chloride (poly-DADMAC) samples having different mean molecular masses and evaluated the adsorbed amounts. Not only did the amount of titrant capable of adsorbing onto the fiber surfaces increase with decreasing molecular mass, but also the adsorbed amount of the lowest-mass poly-DADMAC was decreased if the fibers had been dried and rewetted. The latter observation supports the theory that drying can cause semi-irreversible closure of some of the pores initially present (Stone and Scallan 1966).

Questions remain regarding whether the pores in a cellulosic fiber cell wall constitute a continuous network. Though a continuous network is consistent with an early structural model (Stone and Scallan 1968) and more recent results of microscopy (Alince 2002; Andreasson et al. 2003), it has been suggested that hemicellulosic gel (Lenz et al. 1986) may block such flow. Polyelectrolyte coils are sometimes described as being "non-draining" or "free-draining." Recent work by Rzenhak et al. (1999) suggested that neither the idealized non-draining nor the idealized free-draining concept adequately described the interactions of tethered polymers exposed to flow.

The electrically charged nature of cellulosic fiber surfaces in aqueous media has been characterized by acid-base titrations (Herrington and Petzold 1992; Lloyd and Horne 1993; Bygrave and Englezos 1998; Lindgren et al. 2002), as well as by electrokinetic measurements (Goring and Mason 1950; Chang and Robertson 1967; Goulet and Stratton 1990; Sanders and Schaeffer 1995; Wang and Hubbe 2002). By 
potentiometric analyses of fibers through acid-base titrations, it has been possible to achieve accurate quantification of the content of carboxylic acid groups that are accessible to the solution, as well as the characteristic dissociation constants of those groups. Work by Chen et al. (2004), confirmed the complex nature of the electrokinetics of the fiber surface by demonstrated that the outer "monolayer" of fiber can adsorb more cationic charge than theoretically accessible based on a simple analysis of dissociated carboxylic acid groups. It follows that a three-dimensional view of fibers will be needed in order to account for interactions with polyelectrolytes, even in cases of high molecular mass.

While electrokinetic methods such as microelectrophoresis (Strazdins 1972; Goulet and Stratton 1990; Sanders and Schaeffer 1995) and streaming potential tests involving pads of fibers (Goring and Mason 1950; Chang and Robertson 1967; Penniman 1992; Wang and Hubbe 2001; Hubbe and Wang 2004) can be used to determine the $\mathrm{pH}$ at which cellulosic fiber surfaces are electrically neutral, they do not provide direct information about the charge density of the surfaces. This is because the detected quantity is an electrical potential, rather than a quantification of charged groups. As illustrated in Fig. 1, the electrokinetic signal, the nature of which depends on what type of electrokinetic test is being performed (Hunter 1981), arises due to the relative motion of the fluid past solid surfaces. Counter-ions that exist outside of a hypothetical plane of shear are expected to move with the fluid, creating a net flow of electricity. In streaming potential tests one evaluates the resulting voltage difference across a pad or bed of wetted material, in response to a known application of pressure (Hubbe and Wang 2004).

Relative information pertaining to fiber surface charges can be obtained from electrokinetic measurements if it is assumed that there is a high-affinity, stoichiometric interaction between a cationic polyelectrolyte species and the fiber surfaces (Chen et al 2003; Fardim and Holmbom 2003; Chen et al. 2004; Koljonen et al. 2004; Mathews et al. 2004; Mocchiutti and Zanuttini 2005). Because high-mass polyelectrolytes cannot gain access to all of the acidic sites that are accessible to $\mathrm{H}_{3} \mathrm{O}^{+}$and $\mathrm{OH}^{-}$ions, it is not surprising that such analyses tend to show much lower apparent charge of fiber surfaces, compared to potentiometric tests. Some authors have employed titrants of highly contrasting molecular mass to distinguish charged groups at the outer surface of fibers, relative to a "total charge" that is accessible to the titrant of lower molecular mass (Öhman et al 1997).

Circumstantial evidence related to the porous nature of cellulosic fibers has been obtained in a number of studies in which electrokinetic tests were carried out over a period of time after the substrates had been treated with highly charged cationic polymer (Penniman 1992; Koethe and Scott 1993; Farley 1997; Wang and Hubbe 2002). For example, Farley (1997) observed that the rate of decay of zeta potential increased with decreasing molecular mass and increasing temperature.

Figure 2 illustrates one idealized concept to account for the observed decay of electrokinetic potential following treatment of cellulosic fibers with cationic polymer. In this simple model it is assumed that the pores act as if they are dead-ended cylinders, having one end open to the aqueous solution. Though the Fig. 2 is admittedly an idealization of the actual situation (see, for instance Stone and Scallan 1968), the concept can be used to rationalize why the observed decay of electrokinetic potential tends to be more rapid and more complete in the case of lower-mass cationic polymers (Koethe and 
Scott 1993; Farley 1997). Based on this model, penetration of relatively small macromolecules into pores is expected to result in depletion of those macromolecules from the outer surface of the fiber. The characteristic size of pores in the cell wall, as indicated by solute exclusion, seem to be sufficiently small so that polyelectrolytes of different sizes will have differing ability to get into them (Stone and Scallan 1968; Berthold and Salmén 1997; Alince and van de Ven 1997). Another explanation that is sometimes given to account for such decay of electrokinetic potential with time is that the polyelectrolytes are gradually changing their adsorbed conformation from a more extended form to a flatter form (Wågberg et al. 1988; Wågberg 2000), and that the smaller molecules can undergo such transformations more rapidly. The time constants that have been cited for such conformational changes (Wågberg et al. 1988; Ödberg et al. 1993) are generally too small to explain the present observations. Despite the success of Fig. 2 in explaining decay of electrokinetic potentials, there remains a key inadequacy that deserves comment. The figure, if taken literally, implies that there is no significant flow of liquid through sub-surface regions of the fibers. Evidence of such flow (see Hubbe et al. 2006) is considered later in this article.

Figure 3 illustrates the first of two other idealized models that are being proposed to account for observed effects of time and ionic strength on the streaming potential of polyelectrolyte-treated fibers, as will be described. The surface of the fiber is envisioned as a "forest" of fibrillated cellulose strands, some of which may be of molecular dimensions (Pelton 1993). Though it is known that cellulosic surfaces tend to become more fibrillated as a result of refining (Baker 1995), there is a continuing need to better characterize the nature of the pore spaces within such a layer. In Fig. 3, one can consider two types of flow relative to the surface of the fiber. The conventional way to describe the streaming potential resulting from flow of a liquid through a pad of fibers involves only the outer arrow. Movement of the liquid adjacent to the surface results in a net flow of counter-ions, which balance the net charge of the surface. The flow of electricity resulting from the movement of the counter-ions gives rise to changes streaming potential changes, which can be evaluated with suitable electrode probes on either side of the pad of fibers. In the case of fibers having layers of fibrils at their surfaces, it is reasonable to anticipate that flow also will occur within the spaces between the fibrils. The lower arrow in the figure serves as a reminder that such flows, if they occur, also can be expected to contribute to the observed electrokinetic effects.

Figure 4 illustrates another idealized model, which is based on the assumption that pores within the fiber cell wall function as an inter-connected network, such that there is a net flow in response to an applied pressure. The model assumes the case in which the system has been treated with a solution of cationic polyelectrolyte having a molecular mass sufficiently high that it is essentially excluded from the cell wall pores. Note that if one considers only the flow external to the fiber, one would expect that the addition of a sufficient amount of cationic polyelectrolyte would cause the fibers to have a positive streaming potential. The internal pores, within the cell wall, would be expected to remain negative in charge, assuming that there is significant dissociation of carboxyl groups under the local conditions of $\mathrm{pH}$ (Grignon and Scallan 1980; Fält and Wågberg 2003). Though the model is conceptually consistent with the structure proposed by Stone and Scallan (1968), it has not been demonstrated whether or not such pores are sufficiently connected that they make a significant contribution to measured 
streaming potentials when aqueous solutions are forced through pads of cellulosic fibers. Micrographs published by Alince (2002) also support the idea that pores within the cell walls of never-dried kraft fibers provide continuous paths for aqueous solution.

The experiments carried out in this study can be viewed as an effort to determine which of the three idealized models, Fig. 2, 3, or 4, best accounts for streaming potentials in the case of three types of cellulosic fibers. Independent variables included mean molecular mass of poly-DADMAC, dosage amounts, time, and salt concentrations. In addition, tests were carried out in which the salt concentration was abruptly changed back and forth several times between higher and lower levels. Dewatering rate experiments and retention tests of positively and negatively charged probe particles were used as supplementary methods to determine whether the models diagramed in Figs. 3 and 4 were consistent with the amounts of high-charge cationic polymer required to achieve a neutral streaming potential of the outermost surfaces of fibers.

\section{Experimental}

Experiments were conducted with deionized water (ion-exchange system from Pureflow, Inc.), except where noted otherwise. Inorganic chemicals were of reagent grade. Three kinds of supporting electrolytes were used during the evaluations of streaming potential, dewatering rates, and turbidimetric studies to be described. For tests in the "absence of salt," a $10^{-4}$ molar concentration of sodium bicarbonate was used, giving a $\mathrm{pH}$ of $\mathrm{ca} .7$ and an electrical conductivity of $c a .60 \mu \mathrm{S} / \mathrm{cm}$. A second default condition involved adding sufficient sodium sulfate to the sodium bicarbonate solution in order to increase the electrical conductivity to $1000 \mu \mathrm{S} / \mathrm{cm}$. A third background electrolyte was prepared by adding yet more sodium sulfate, resulting in a conductivity of $5000 \mu \mathrm{S} / \mathrm{cm}$.

The high-charge cationic polyelectrolytes used in the study were polydiallyldimethylammonium chloride (poly-DADMAC) from the Aldrich catalogue, numbers 52,237-6 (very low mass), 40,901-4 (low mass) and 40,903-0 (high mass). The nominal molecular masses of the products are given as 5-20,000, 100-200,000, and 400500,000 , respectively.

Probe particles having fixed positive or negative electrokinetic charge were prepared from ca. $20 \mu \mathrm{m}$ microcrystalline cellulose powder, product 31,069-7 from Aldrich. The reagent used to prepare negatively charged probe particles was 3-chloro-2hydroxy-1-propanesulfonic acid, sodium salt hydrate, $95 \%$ from Aldrich. The reagent used to prepare positively charged probe particles was (3-chloro-2-hydroxypropyl) trimethyl-ammonium chloride, $60 \mathrm{wt} . \%$ solution in water. To make the positively charged particles, $20 \mathrm{~g}$ of MCC were added to $180 \mathrm{~g}$ deionized water with $2.15 \mathrm{~g}$ of $60 \%$ trimethylammonium chloride and $100 \mathrm{~g}$ of $8 \% \mathrm{NaOH}$ prepared in saturated $\mathrm{NaCl}$ solution. The mixture was reacted under agitation for $18 \mathrm{~h}$ at $45^{\circ} \mathrm{C}$. The negatively charged particles were prepared similarly, except that $13.6 \mathrm{~g}$ of $95 \%$ 2-chloro-2-hydroxy-1propanesulfonic acid was used as the reagent. The solid product was rinsed multiple times with deionized water. Zeta potentials were evaluated in the presence of sodium sulfate solution having a conductivity of $1000 \mu \mathrm{S} / \mathrm{cm}$. The zeta potential of the cationic derivatized particles was nearly constant at about $+18 \mathrm{mV}$ within the range $3<\mathrm{pH}<8$. The zeta potential of the anionic derivatized particles was about in the range -20 to $-30 \mathrm{mV}$ for $\mathrm{pH}$ values of 3 or more. 
Conventional bleached hardwood kraft pulp from Southern US wood species was obtained in dry-lap form and disintegrated. Part of the kraft pulp was further subjected to 30 minutes of refining in a laboratory Hollander beater (Valley Machinery Co., Appleton, WI, see TAPPI method T200). The refined fiber slurry was then placed, one-quarter of the batch at a time, into the final vessel of a Bauer-McNett classifier (TAPPI Method T233), using a 200-mesh screen. The apparatus was run for ten minutes and the fines fraction was discarded. The chemi-thermomechanical pulp (CTMP) used in some of the experiments was a mixture of 80\% product Q120/60 and 20\% product Q400/B70 from Quesnel River company. The CTMP was dispersed and not subjected to any additional refining or fractionation.

Streaming potential tests, to determine the electrokinetic nature of the cellulosic surfaces, were carried out with the SPJ device described elsewhere (Wang, Hubbe 2001). Briefly stated, $3.5 \mathrm{~g}$ of fiber on an oven-dry basis was prepared in $750 \mathrm{ml}$ supporting electrolyte. Streaming potentials were determined with a pressure differential of $207 \mathrm{kPa}$ across the pad of fibers.

Retention tests were carried out with a Dynamic Drainage/Retention Jar, as described by Britt (1973), using a machined screen with conical holes having minimum diameter of $70 \mu \mathrm{m}$ (small opening facing upwards). Fines-free, refined kraft fiber slurry of $0.5 \%$ solids was placed in the vessel and agitated at $500 \mathrm{rpm}$. After $15 \mathrm{~s}$ of stirring, the fiber slurry was optionally treated with high-mass poly-DADMAC (Aldrich cat. no. 40,903-0) at levels described in the text. After an additional $15 \mathrm{~s}$ of stirring, the agitation rate was reduced to $250 \mathrm{rpm}$., and probe particles of positive or negative charge were added in incremental amounts. After each such addition, agitation was continued for $30 \mathrm{~s}$, then the filtrate was sampled, returning the first $20 \mathrm{ml}$ untested to the stirred vessel. Turbidity measurements were obtained with a DRT-15CE turbidimeter. Five replicate measurements were made of each mixture. Calibration tests were carried out with the MCC probe particles of either change added at increasing levels to the Britt Jar in the absence of fibers.

\section{Results and discussion}

Streaming potential vs. polymer dosage, time, and sodium sulfate

As shown in Fig. 5, initial addition of poly-DADMAC to fiber suspensions caused an immediate rise in streaming potential to less negative or more positive values. For instance, Fig. 5A shows that $0.02 \%$ of low-mass poly-DADMAC, based on fiber dry mass, was sufficient to reverse the initially negative sign of streaming potential in the absence of added salt. Thereafter, the streaming potential began to decay back in the direction of its initial state prior to the polymeric treatment. A second, equal dosage of poly-DADMAC, added after an elapsed time of 12 minutes, reversed the streaming potential to positive, but the value of streaming potential decayed again, resulting in a near-zero streaming potential after an additional 10 minutes of continued stirring. Strikingly similar results were obtained in the case of refined kraft fibers in the absence of fines (Fig. 5B) and in the case of unrefined whole kraft pulp treated with sufficient sodium sulfate to raise the conductivity to $1000 \mu \mathrm{S} / \mathrm{cm}$ (Fig. 5C). In each case it was possible to adjust the amount of poly-DADMAC such that a near-zero streaming 
potential was achieved (a) immediately after the first addition and (b) after a second, equal addition of the polymer, following approximately 10 minutes of further stirring. Similar results also were obtained in the case of CTMP fibers (not shown).

To further explore the effects of molecular mass and sodium sulfate on the amounts of poly-DADMAC required to achieve zero streaming potential, the endpoints of various titrations are compared in Fig. 6. As shown, the amount of cationic polymer needed to neutralize the fibers increased extremely abruptly with increasing salt concentration (note the logarithmic scale of the vertical axis). In agreement with some previous work (Wang and Hubbe 2002), greater amounts of lower-mass cationic polymer were needed in order to achieve a neutral electrokinetic potential. As shown in Part B of the figure, similar trends were observed in the case of refined, fines-free kraft fibers. The trends in both sets of results are consistent with the model shown in Fig. 2, though the models shown in Figs. 3 or 4 cannot be ruled out as explanations of the data.

Though the indications given by the effects of salt concentration can be rationalized in terms of polyelectrolyte conformations, the very high factors by which the endpoints changed with salt suggest a different origin for the observed effect. Thus, a less extended average conformation of the polyelectrolytes is expected with increasing salt, due to shielding of electrostatic forces and a shortening of the Debye length (Hiemenz and Rajagopalan 1997). The degree to which a polyelectrolyte contracts due to salt can be estimated (de Gennes 1979; Mandel 1985). If one neglects salt-induced effects on the persistence length, it would be predicted that an increase ionic strength from $10^{-4}$ to $7.9 \times 10^{-3}$ molar, corresponding to the employed solutions of 60 and 1000 $\mu \mathrm{S} / \mathrm{cm}$ conductivity, would decrease the Debye-Hückel length $\kappa^{-1}$ from approximately 34 $\mathrm{nm}$ to $3.4 \mathrm{~nm}$. Such a change is expected to change the root-mean-squared end-to-end distance by a factor of 0.63 (de Gennes 1979). By contrast, Fig. 6 shows changes by factors of 5 to 20 when comparing endpoints for the conductivity conditions 60 and 1000 $\mu \mathrm{S} / \mathrm{cm}$. The alternative explanation will be offered after considering a further piece of evidence.

\section{Reversibility of streaming potentials with changes in salt concentration}

The results shown in Fig. 6 suggest, but do not prove that the sign of streaming potential will change if the salt content is either increased or decreased after the poly-DADMAC treatment and the first measurement of streaming potential. In other words, suppose that enough poly-DADMAC is added so that tests with a background conductivity of 60 $\mu \mathrm{S} / \mathrm{cm}$ show a distinctly positive streaming potential. Tests were carried out to determine whether that potential would change to negative if salt were added, as suggested by the results of tests carried out with the salt present throughout the experiment. Likewise, there was a desire to find out whether the streaming potential would become positive again if the salt concentration is once again lowered. These tests were needed in order to rule out certain alternative explanations of the results in Fig. 6. For instance, one might suppose that a change in salt concentration could cause adsorbed polyelectrolytes to either penetrate into small pores or to become desorbed from the substrate.

Figure 7 shows the results of an experiment carried out roughly in the manner suggested in the previous paragraph. The initial addition of polymer was in the absence of sodium sulfate, and the electrical conductivity was approximately $60 \mu \mathrm{S} / \mathrm{cm}$. 
Incremental amounts of $0.3 \%$ poly-DADMAC (low mass) on fiber solids were added in three stages, such that a positive streaming potential was achieved. Then, after cycle 7 , the electrical conductivity was abruptly increased to $1000 \mu \mathrm{S} / \mathrm{cm}$ by dewatering the fibers through a 200-mesh screen and resuspending them in salt-containing buffer solution, as described earlier. As shown, the change in electrolytic conditions yielded an immediate change to a negative streaming potential. Next, at cycle 12, the fibers were dewatered again, and the filtrate was replaced by salt-free buffer solution. As shown, the streaming potential reverted to positive. The same sequence of changes in salt concentration was repeated yet another cycle, with basically the same results. With the passage of time, however, it was clear that a "decay" phenomenon also was significantly affecting the results. The maximum streaming potential, achieved at each time the conductivity was $60 \mu \mathrm{S} / \mathrm{cm}$, due to the use of salt-free solution, decreased gradually with time. The decay effect confirms the results already shown in Fig. 5.

The fact that the streaming potential could be repeatedly reversed by varying the ionic strength helps to rule out the possibilities that changes in salt concentration either cause the polyelectrolyte to adsorb much more rapidly into pores or to desorb. Rather, the effects of salt appear to be a consequence of how streaming potentials of polyelectrolyte-treated nanoporous substrates are evaluated.

Turning again to Figs. 3 and 4, one way to account for the oddly reversible electrokinetic effects resulting from changes in salt concentration is to assume that the polyelectrolyte initially adsorbs mainly on the outer surfaces of the fibers. Because there is expected to be a continuous network of aqueous solution among the fibrils (Fig. 3) and within the cell walls (Fig. 4), flow occurs not only past the outer-most surface, but also below the level at which the adsorbed polyelectrolytes are present. In theory, a contribution to the net streaming potential signal can arise due to each of these kinds of flow. Let us further assume that at a very low electrical conductivity only the outermost surfaces significantly contribute to the streaming potential results. Such an assumption is expected to be true in cases where the Debye-Hückel length is larger relative to the characteristic size of pores (Hunter 1981; Kozak and Davis 1986; Miller et al 1992; Wan 1997; Bernabé 1998; Revil et al. 1999; Alkafeef et al 2001). In common terms, electrokinetic effects, such as zeta potential, can be suppressed within very small pores due to the fact that there is not sufficient space to accommodate an ionic double layer.

The mechanism suggested in the previous paragraph recently has been demonstrated in the case of nanoporous silica gel, suspended in aqueous solutions (Hubbe et al. 2006). Silica gel is an interesting model substance, with which to compare the impact of cellulose fibers' nanoporous nature effects due to adsorption of cationic polymers. Silica gel has a more well-defined pore size that does not swell or collapse to a significant extent in response to changes in aqueous conditions (see Hostetler and Swanson 1974). To summarize the recent work, it was possible to reverse the sign of streaming potential repeatedly, just by changing the salt concentration, following treatment of the silica gel suspensions with an amount of cationic polyelectrolyte that was above the adsorption capacity of the solids (Hubbe et al. 2006). The reversal of the (electrokinetic) sign occurs because the contribution of the smallest pores is strongly suppressed in the absence of salt, and the contribution of the outer surfaces is affected by the adsorbed polyelectrolytes. Upon addition of salt, the observed electrokinetic signals 
result from a combination of both the polymer-covered outer surfaces and the negatively charged surfaces of nanopores that are essentially inaccessible to the polyelectrolytes.

\section{Consideration of alternative explanations}

Though the models depicted in Figs. 3 and 4, together with the suppression of electrokinetic effects within very small pores at low ionic strength, appear to account for the main effects shown in Figs. 5 through 7, various other established concepts in colloid chemistry should not be overlooked as alternative explanations. Table 1 lists a number of candidate explanations that either were considered by the authors or were suggested by others.

\begin{tabular}{|c|c|}
\hline Candidate explanation & Key deficiencies in the explanation \\
\hline $\begin{array}{l}\text { 1. Increasing salt screens electro- } \\
\text { static effects, causing more compact } \\
\text { conformations of polyelectrolytes } \\
\text { (Lin and Cheng 2000). }\end{array}$ & $\begin{array}{l}\text { Effects of salts on polyelectrolyte conformation } \\
\text { cannot account for reversals of sign of streaming } \\
\text { potential with varying ionic strength. }\end{array}$ \\
\hline $\begin{array}{l}\text { 2. Increased salt can change the } \\
\text { adsorbed conformation of cationic } \\
\text { polyelectrolytes on negative surfaces } \\
\text { from flat to three dimensional (see } \\
\text { van de Steeg et al. 1992; Rojas et al. } \\
1998 \text {; Horvath et al. 2006). }\end{array}$ & $\begin{array}{l}\text { If such a change were to occur, upon addition of } \\
\text { sodium sulfate to poly-DADMAC-treated fibers, } \\
\text { the extension of polyelectrolyte segments away } \\
\text { from the surface would increase, rather than } \\
\text { increase the positive electrokinetic influence of } \\
\text { the chain segments (see Ohshima 1997). }\end{array}$ \\
\hline $\begin{array}{l}\text { 3. Cellulosic fibers conduct } \\
\text { electricity, an effect that is expected } \\
\text { to influence the streaming potentials, } \\
\text { especially at low ionic strength } \\
\text { (Scallan 1989; van de Ven 1999). }\end{array}$ & $\begin{array}{l}\text { Such conductivity, in the context of the present } \\
\text { work, would be expected to decrease the } \\
\text { magnitude of the measured streaming potential } \\
\text { with no significant effect on the sign or on the } \\
\text { amounts of polyelectrolyte required to reach a } \\
\text { neutral condition. }\end{array}$ \\
\hline $\begin{array}{l}\text { 4. Abrupt changes in ionic strength } \\
\text { are expected to result in gradients of } \\
\text { ionic strength from the outside to the } \\
\text { inside of nanoporous fibers (see, e.g. } \\
\text { Ala-Kaila and Alén 1999). It was } \\
\text { suggested that such gradients might } \\
\text { affect streaming potential results. }\end{array}$ & $\begin{array}{l}\text { Near the fiber surfaces, the high mobility of salt } \\
\text { ions makes it unlikely that significant effects } \\
\text { would have been observed due to salt gradients } \\
\text { under the conditions of the present study. } \\
\text { Regarding flow through fiber walls, any effects } \\
\text { due to positive and negative gradients of } \\
\text { concentration would be expected to cancel each } \\
\text { other out, because streaming potential tests } \\
\text { involve flow from one side to the other. }\end{array}$ \\
\hline $\begin{array}{l}\text { 5. Coverage of the fiber exteriors by } \\
\text { polyelectrolytes may be reversible } \\
\text { upon addition of salt (van de Steeg et } \\
\text { al. 1992; Wågberg 2000). }\end{array}$ & $\begin{array}{l}\text { The aqueous solution was replaced repeatedly } \\
\text { with polyelectrolyte-free solution when } \\
\text { demonstrating of the reversibility streaming } \\
\text { potential. }\end{array}$ \\
\hline $\begin{array}{l}\text { 6. The effective density of ionic } \\
\text { charge of polyelectrolyte gels tends to } \\
\text { increase as the gel shrinks (Makino et }\end{array}$ & $\begin{array}{l}\text { Data in the cited article show, nevertheless, that } \\
\text { the net effect of increased salt is to decrease the } \\
\text { magnitude of streaming potential. In other }\end{array}$ \\
\hline
\end{tabular}


al. 1995). The effect suggests increased streaming potential of gel surfaces with increasing salt.

7. Fibrillar layers, as well as the pores within cell walls may consist of hemicellulose gels, which can impede flow (Lenz et al. 1986; Schlesinger et al. 2005). words, the salt ions do not cause sufficient deswelling to overcompensate the usual effect of salt tending to reduce streaming potentials. Very little fluid flow is needed to create a significant streaming potential signal, e.g. in the case of very small pores. Thus, the present tests may represent a very sensitive way to detect the occurrence of such flows. Other work suggests that flow does occur through gel layers (Makino et al. 1995)

Various reasons can be offered in support of either flow within fibrillar layers (Fig. 3) or through cell walls (Fig. 4) as having a more dominant effect on the results presented in Figs. 5 through 7. The fact that similar results were achieved with refined and unrefined kraft fibers (see Figs. 5 and 6) tends to weaken an explanation based solely on flow occurring through very small pores within fibrillar layers at fiber surfaces. This argument requires that one assume that refining affects the degree of fibrillation on a very fine scale, as would be detected by the present methods. The fact that similar decay phenomena were observed for both chemical and mechanical pulp fiber slurries tends to weaken explanations that are based only on the nanoporosity of the cell walls, neglecting any effects due to fibrillation. Mechanical pulp fibers are known to have much smaller pores, in comparison to kraft fibers (Berthold and Salmén 1997). In addition, the sizes of pores within the cell walls of fibers are expected to affect the degree to which electrokinetic effects are suppressed under conditions of low ionic strength (Hunter 1981; Kozak and Davis 1986; Miller et al 1992; Wan 1997; Bernabé 1998; Revil et al. 1999; Alkafeef et al 2001). In light of these issues, further work involving well characterized systems is justified.

\section{Dewatering rate maxima in comparison with streaming potential endpoints}

Because the idealized models depicted in Figs. 3 and 4 appear to qualitatively explain the observed electrokinetic effects, further evidence was sought to either support or contradict these models. Various past studies have suggested that rates of dewatering ought to be maximized when just enough high-charge cationic material has been added to a papermaking system to neutralize the colloidal charge (Davison and Cates 1975; Horn and Melzer 1975; Farinato et al. 1999). It is reasonable to suppose that neutralization of the outer surfaces of fibers should correspond to maximum dewatering, since the outer surfaces, rather than charges buried under a layer of fibrillation or within cell walls, would be expected to dominate colloidal interactions between fibers and with cellulosic fines (Hiemenz and Rajagopalan 1997). This expectation is based on an assumption that dewatering rate effects are dominated by colloidal forces acting between suspended matter and between individual fibrils on fibers and fines (Maunier and Ramarao 1996; Hubbe 2002).

To test the hypothesis just stated, Fig. 8 summarizes the results of streaming potential titration tests involving three kinds of fiber suspensions, three poly-DADMAC titrants having different molecular mass, and two contrasting conditions of electrical 
conductivity. Using the standard features of the SPJ device (Wang and Hubbe 2001), both the streaming potential and the amount of filtrate passing through the screen were recorded during the course of each titration. The plotted circles in Fig. 8 indicate the levels of poly-DADMAC corresponding to the maximum dewatering rate in each case. The potted diamond shapes correspond to the polymer dosages yielding zero streaming potential under various conditions of electrical conductivity, pulp type and titrant mass. The darker symbols, as well as the solid lines tying data points together, correspond to the higher salt concentration in each case. In one case there were two observable maxima in dewatering rate. In another case (unrefined whole pulp, very-low-mass titrant) no maximum in the dewatering rate was observed.

The data in Fig. 8 support the stated hypothesis in the following way: At low salt concentration the poly-DADMAC amounts yielding maximum dewatering rates were consistently within a factor of two relative to the amounts required to achieve neutral streaming potential in the same mixture. In addition, the poly-DADMAC amounts providing maximum dewatering rates for the higher-salt conditions (dark circles) were typically between four and ten times lower than the corresponding amounts for achieving zero streaming potential. The contrast can be seen in the much greater length of the solid horizontal lines, compared to the dotted lines in the figure. In most cases the streaming potential endpoints in the absence of salt were better predictors for the conditions of maximum dewatering, even when considering dewatering rates evaluated in the presence of salt. In general, the data support the use of low conductivity conditions for evaluation of the fibers' external potential, as a means of optimizing dewatering rates.

\section{Retention of probe particles}

Retention tests with probe particles were used to further evaluate the hypothesis that lowconductivity streaming potential measurements (or possibly extrapolations to lowconductivity conditions) can be used as a basis for monitoring the electrokinetic condition of the outer surfaces of fibers. For ease of interpretation, these tests were carried out using fines-free bleached kraft fibers. Figure 9 shows the results of preliminary tests to help select the poly-DADMAC dosages to be used in these tests. As shown, $0.013 \%$ of poly-DADMAC (high mass) was required to achieve neutral streaming potential at 60 $\mu \mathrm{S} / \mathrm{cm}$, whereas $0.044 \%$ was needed at the higher salt concentration yielding $1000 \mu \mathrm{S} / \mathrm{cm}$ conductivity. The turbidities of suspensions of charged MCC particles showed highly linear and reproducible relationships $v s$. the amount added to the background electrolyte. The curves for positively and negatively charged MCC suspensions were in close agreement.

Figure 10 contrasts retention results for two extreme situations, zero initial addition of poly-DADMAC to the fibers (Part A) and addition of excess poly-DADMAC, followed by rinsing of the fibers (Part $B$ ). Thus, the streaming potentials of the fibers were either negative in charge (A) or clearly positive (B), over the whole range of electrical conductivities considered. The turbidity results show a significant effect, dependent on the charged nature of the probe particles. In the case of untreated fibers the positively charged MCC probe particles were retained preferentially, yielding lower values of turbidity in the filtrate. By contrast, positively charged fibers, that had become saturated with poly-DADMAC, preferentially retained the negatively charged MCC. The 
fact that the results tended to show higher contrast in salt-free suspensions is consistent with the longer range and greater effectiveness of electrostatic forces under those conditions (Hiemenz and Rajagopalan 1997). The diagonal line in each part of the figure is based on the calibration curve for the MCC particles, if it were assumed that none of the particles were retained on the fibers in the Britt Jar test.

As a critical test of the hypotheses represented by Figs. 3 and 4, Fig. 11 considers two intermediate levels of poly-DADMAC treatment corresponding to points " 1 " and " 2 " in Fig. 9. It was found that a treatment level of just $0.0065 \%$ poly-DADMAC on fiber solids (level "1") yielded turbidity results that were the least dependent on the sign of charge of the MCC probe particles. In other words, the positive and negative particles appeared to be retained about equally at each level of addition to the fibers. Notably, results corresponding to tests in the presence and in the absence of salt were quite close together, which is what one would expect if, in fact, the outer surface of the fibers really does have a zero effective charge at that level of treatment. Part B of the figure shows that at a treatment level of $0.013 \%$ poly-DADMAC (level " 2 "), the fibers surfaces were already acting as if they had an effective positive charge, in terms of retention of the MCC particles. Thus, as in part B of Fig. 11, the negative MCC particles were retained more efficiently than the positive particles, and the effects were amplified in the absence of salt.

Similar tests also were carried out for the levels described as conditions " 3 " and "4" in Fig. 9, corresponding to $0.025 \%$ and $0.044 \%$ poly-DADAMC on cellulose, respectively. Results were essentially the same as those obtained after the fibers had been saturated with 1\% poly-DADMAC, then rinsed (see Fig. 10B). In other words, the fibers acted as if they had a positive charge. The evidence of positive charge was found even if the retention tests were carried out in the presence of sufficient sodium sulfate to raise the electrical conductivity to $1000 \mu \mathrm{S} / \mathrm{cm}$, the salt level at which the streaming potential of fibers was zero at a level of poly-DADMAC application corresponding to condition "4" in Fig. 9. Though the foregoing explanation has not dealt explicitly with the uniformity of the polyelectrolyte layer on the fiber surface, there is reason to expect discontinuous, patch-like adsorbed layers at intermediate levels of polymer addition (Kasper 1971; Gregory 1976; Akari et al. 1996).

To summarize results in Figs. 7, 8, and 11, it appears that streaming potential tests, when carried out in the presence of salt, do not sense just the charged condition of the outer surfaces of fibers. Rather, in order to obtain critical information needed for optimization of retention effects in the presence of low to moderate mass cationic polymers, it appears that the streaming potential tests should be carried out at a very low electrical conductivity. Two approaches might be considered in future work in order to implement such tests in a paper mill. On the one hand, furnish samples might be dewatered on a screen, replacing the filtrate with distilled water. On the other hand replicate tests of streaming potential could be carried out with supplementary addition of salt, making it possible to extrapolate the data and estimate the value of titration endpoints corresponding to very low conductivity. While either of these procedures is more complicated than published methods of streaming potential analysis (Penniman 1992; Hubbe and Wang 2001; Hubbe and Wang 2004), either procedure could easily be carried out with modern automation. 
The present results also shed light on the structure and permeability of cellulose fibers. The fact that the sign of streaming potential results depended on salt concentration is strong evidence that (a) the cationic polyelectrolytes employed in the work were mainly held out at the outer surfaces of the fibers, and (b) a finite amount of flow occurred through the fibers, below the level accessible to the cationic polyelectrolyte molecules. The present results cannot clearly distinguish whether such flow occurred through a jungle of nanofibrillar material at the fiber surfaces (as illustrated in Fig. 3), or whether such flow occurs through the fiber walls (Fig. 4).

\section{Conclusions}

1. The nanoporous nature of cellulosic fibers was found to significantly affect the electrokinetic properties, following treatment with high-charge cationic polymers. The decay of streaming potential values with time, following the polymer treatments, was consistent with diffusion of the polyelectrolyte into locations where they have much less effect on the observed electrokinetic potentials. Effects of molecular mass also were consistent with the presence of pores having widths in the range of tens of nanometers.

2. Effects of changes in salt concentration on streaming potentials could best be explained by a model in which a continuous network of very small pores exists below the surface of cellulosic fibers in locations not readily accessible to the polyelectrolyte used in this study. Polymers remaining on the outermost surfaces of fibers, due to their high molecular mass, dominate the results of streaming potential tests carried out in the absence of salt, due to the fact that pore spaces below the outermost surface tend to be narrower than the dimensions of ionic double layers under those salt conditions. By contrast, results of electrokinetic tests in the presence of salt suggest that surfaces of pores that are too small to admit significant amounts of cationic polymer tended to remain negative in potential, despite treatment of the fibers with cationic polymer.

3. Though results of the present study suggest that flow of aqueous solution takes place below the surface of cellulosic fibers, in response to an applied pressure, more work would be required to quantify such flow.

4. The sign of charge of the outer-most surfaces of polyelectrolyte-treated cellulosic fibers is best evaluated by carrying out the streaming potential tests at low electrical conductivity. Results of such low-conductivity tests of streaming potential can be expected to agree more closely with optimum conditions for dewatering and retention, compared to results of tests carried out at higher conductivity.

\section{Acknowledgements}

The authors are grateful for in-kind support from the Hansol Paper Company of Korea, who supported Taemin Jung as a visiting scientist. Additional support of the Buckman Foundation is gratefully acknowledged. 


\section{References}

Akari, S., Schrepp, W., and Horn, D. 1996. Imaging of single polyethylenimine polymers adsorbed on negatively charged latex spheres by chemical force microscopy. Langmuir 12 (4): 857-860.

Ala-Kaila, K., and Alén, R. 1999. Dynamic response in $\mathrm{pH}$ and the transient behavior of some chemical elements in pulp-water suspensions. Nordic Paper Paper Res. J. 14 (2): 149-157.

Alince, B. 2002. Porosity of swollen pulp fibers revisited. Nordic Pulp Paper Res. J. 17 (1): 71-73.

Alince, B. and Van de Ven, T. G. M. 1997. Porosity of swollen pulp fibers evaluated by polymer adsorption, in Barker, C. F., Ed., The Fundamentals of Papermaking Materials, Vol. 2, PIRA, Leatherhead, UK, p. 771-789.

Alkafeef, S., Gochin, R. J. and Smith A. L 2001. The effect of double layer overlap on measured streaming currents for toluene flowing through sandstone cores. Colloids Surf. A 195 (1-3): 77-80.

Andreasson, B., Forsström, J., and Wågberg, L. 2003. The porous structure of pulp fibers with different yields and its influence on paper strength, Cellulose 10: 111-123.

Baker, C. F. 1995. Good practice for refining the types of fiber found in modern paper furnishes. Tappi J. 78 (2): 147-153.

Bernabé, Y. 1998. Streaming potential in heterogeneous networks. J. Geophys Res. 103 (B9): 20,827-20,841.

Berthold, J. and Salmén, L. 1997. Effects of mechanical and chemical treatments on the pore-size distribution of wood pulps examined by inverse-size-exclusion chromatography (ISEC). J. Pulp Paper Sci. 3 (6): J245-J253.

Britt, K.W. 1973. Mechanisms of retention during paper formation. Tappi 56 (10): 46-50.

Bygrave, G. and Englezos, P. 1998. Fiber charge from potentiometric titration of kraft pulp and Donnan equilibrium theory. Nordic Pulp Paper Res. J. 13 (3): 220-224.

Chang, M. Y. and Robertson, A. A. 1967. Zeta potential measurements of fibers. D-C. streaming current method. Can. J. Chem. Eng. 45 (2): 66-71.

Chen, J., Heitmann, J. A. and Hubbe, M. A. 2003. Dependency of polyelectrolyte complex stoichiometry on the order of addition. 1. Effect of salt concentration during streaming current titrations with strong poly-acid and poly-base. Colloids Surf. A 223 (1-3): 215-230.

Chen, S.-L., Wang, S. and Lucia, L.A. 2004. New insights into the fundamental nature of lignocellulosic fiber surface charge. J. Colloid Interface Sci. 275 (2): 392-397.

Davison, R.W. and Cates, R.E. 1975. Electrokinetic effects in papermaking systems: Theory and practice. Paper Technol. Ind. 16 (2): 107-114.

de Gennes, P. G. 1979. Scaling concepts in polymer physics, Cornell Univ. Press, Ithaca, NY.

de Ruvo, A. and Htun, M. 1983. Fundamental and practical aspects of paper-making with recycled fibres, in The role of fundamental research in paper making, J. Brander, Ed., Vol. 1, Mechanical Engineering Publ. Ltd., London. 
Duchesne, I., and Daniel, G. 1999. The ultrastructure of wood fibre surfaces as shown by a variety of microscopical methods - A review. Nordic Pulp Paper Res. J. 14: 129-139.

Fält, S. and Wågberg, L. 2003. Influence of electrolytes on the swelling and strength of kraft-liner pulps, Nordic Pulp Paper Res. J. 18 (1): 69-73.

Farley, C. E. 1997. Factors influencing the rate of charge decay. Tappi J. 80 (10): 177183.

Falth, H.-J. and Scholz, C. 1993. Characterization of accessible structural regions in cellulosic fibers. Melliand Textilberichte/Intl. Textile Rep. 74 (3): 219-221, E100101.

Fardim, P. and Holmbom, B. 2003. Fast determination of anionic groups in different pulp fibers by methylene blue sorption. Tappi J. 2 (10): 28-32.

Farinato, R.S., Huang, S.-Y. and Hawkins, F. 1999. Polyelectrolyte-assisted dewatering. In Colloid-Polymer Interactions, Farinato, R.S. and Dubin, P.L. (Editors), WileyInterscience, New York, pp. 3-50.

Fleer, G. J., Cohen Stuart, M. A., Scheutjens, J. M. H. M., Cosgrove, T. and Vincent, B. 1993. Polymers at Interfaces, Chapman and Hall, London, 1993.

Goring, D. A. I. and Mason, S. G. 1950. Electrokinetic properties of cellulose fibers. Can. J. Res. B28 (6): 307-322; 323-338.

Goulet, M.T. and Stratton, R.A. 1990. The effect of pulping, bleaching, and refining operations on the electrokinetic properties of wood fines. Nordic Pulp Paper Res. J. 5 (\#): 118-125.

Gregory, J. 1976. The effect of cationic polymers on the colloidal stability of latex particles. J. Colloid Interface Sci. 55 (1): 35-44.

Grignon, J. and Scallan, A.M. 1980. Effect of $\mathrm{pH}$ and neutral salts upon the swelling of cellulose gels. J. Appl Polymer Sci. 25 (12): 2829-2843.

Gruber, E., Grossmann, K. and Schempp, W. 1996. Interactions of synthetic cationic polymers with fibers and fillers; influence on adsorption, Wochenbl. Papierfabr. 124 (1): 4-11.

Herrington, T. M. and Petzold, J. C. 1992. An investigation into the nature of charge on the surface of papermaking woodpulps. 1. Charge/pH isotherms. Colloids Surf. 64 (2): 97-108.

Hiemenz, P.C. and Rajagopalan, R. 1997. Principles of Colloid and Surface Science. $3^{\text {rd }}$ Ed., Dekker, New York.

Horn, D. and Melzer, J. 1975. The effect of high molecular mass cationic dewatering aids on the electrokinetic behavior of pulp fibers. Papier 29 (12): 534-540.

Horvath, A.E., Lindström, T., and Laine, J. 2006. On the indirect polyelectrolyte titration of cellulosic fibers. Conditions for charge stoichiometry and comparison with ESCA. Langmuir 22: 824-830.

Hostetler, R.E. and Swanson, J.W. 1974. Diffusion into and adsorption of polyethylenimine on porous silica gel. J. Poly. Sci. 12 (1): 29-43.

Hubbe, M.A. 2002. Fines management for increased paper machine productivity. Proc. Sci. Tech. Advan. Wet End Chemistry, Pira International, Leatherhead, UK.

Hubbe, M.A., Rojas, O.J., Lee, S.Y., Park, S., and Wang, Y. 2006. Distinctive electrokinetic behavior of nanoporous silica particles treated with cationic polyelectrolyte. Colloids Surf. A, in press, available online. 
Hubbe, M. A. and Wang, F. 2004. Charge-related measurements - A reappraisal. Part 2: Fiber-pad streaming potential. Paper Technol. 45 (9): 27-34.

Hunter, R. J. 1981. Zeta Potential in Colloid Science, Academic Press, London.

Kasper, D. R. 1971. Theoretical and experimental investigations of the flocculation of charged particles in aqueous solutions by polyelectrolytes of opposite charge. $\mathrm{Ph}$. D. Diss., California Inst. Technol.

Koethe, J. L. and Scott, W. E. 1993. Polyelectrolyte interactions with papermaking fibers: The mechanism of surface-charge decay. Tappi J. 76 (1): 123-133.

Koljonen, K., Mustaranta, A. and Stenius, P. 2004. Surface characterization of mechanical pulps by polyelectrolyte adsorption. Nordic Pulp Paper Res. J. 19 (4): 495-505.

Kozak, M. W. and Davis, E. J. 1986. Electrokinetic phenomena in fibrous porous media. J. Colloid Interface Sci. 112 (2): 403-411.

Laivins, G. V. and Scallan, A. M. 1993. The mechanism of hornification of wood pulps, in Baker, C. F., Ed., Products of Papermaking, Vol. 2, PIRA, Leatherhead, p. 1235.

Lenz, J., Shurz, J., and Ujhely, W. 1986. Die Gelierung von HemicelluloseSuspensionen. Rheologica Acta. 25: 418-425.

Li, T.-Q., Henrikson, U. and Ödberg, L. 1993. Determination of pore sizes in wood cellulose fibers by ${ }^{2} \mathrm{H}$ and ${ }^{1} \mathrm{H}$ NMR. Nordic Pulp Paper Res. J. 8 (3): 326-330.

Lin, K.-F., and Cheng, H.-L. 2000. A simple method to estimate chain conformations of polyelectrolytes in the semidilute regime. Macromolecules 33: 4961-4965.

Lindgren, H., Öhman, L.-O., Gunnars, S. And Wågberg, L. 2002. Charge determinations of cellulose fibers of different origin - Comparison between different methods. Nordic Pulp Paper Res. J. 17 (1): 89-96.

Lloyd, J.A. and Horne, C.W. 1993. The determination of fiber charge and acidic groups of radiata pine pulps. Nordic Pulp Paper Res. J. 8 (1): 48-67.

Makino, K., Suzuki, K., Sakurai, Y., Okano, T., and Ohshima, H. Electroosmotic flow on a poly(N-isopropylacrylamide) hydrogel surface. Colloids Surf A 103: 221-226.

Maloney, T.C., Johansson, T. and Paulapuro, H. 1998. Removal of water from the cell wall during drying. Paper Technol. 39 (6): 39-47.

Mandel, M. 1985. Polyelectrolytes. Encyclopedia of Polymer Science and Engineering, J. I. Kroschwitz, Ed., Wiley, New York.

Mathews, J., Gustafson, R. and Hodgson, K. 2004. A method to determine the charge demand of single pulp fibers. Nordic Pulp Paper Res. J. 19 (4): 453-459.

Maunier, C. O., and Ramarao, B. V. 1996. Effect of flocculation on pulp drainage characteristics. Proc. TAPPI 1996 Engineering Conf., TAPPI Press, Atlanta, 221238.

Miller, N.P., Berg, J.C. and O’Brien, R.W. 1992. The electrophoretic mobility of a porous aggregate. J. Colloid Interface Sci. 153 (1): 237-243.

Mocchiutti, P. and Zanuttini, M.A. 2005. A useful equation for estimating the surface charge of pulp fibers. Tappi J. 4 (5): 18-22.

Ödberg, L., Tanaka, H., and Swerin, A. 1993. Kinetic aspects of the adsorption of polymers on cellulosic fibers. Nordic Pulp Paper Res. J. 8 (1): 6-9,47.

Öhman, L.-O., Wågberg, L., Malmgren, K. and Tjernström, Å. 1997. Adsorption of aluminum (III) on cellulosic fibers in neutral to alkaline solutions - Influence of charge and the size of the particles formed. J. Pulp Paper Sci. 23 (10): J467-J474. 
Ohshima, H. 1997. Electrophoretic mobility of a polyelectrolyte-adsorbed particle: Effect of segment density distribution. J. Colloid Interface Sci. 185 (1): 269-273.

Pelton, R. 1993. A model of the external surface of wood pulp fibers. Nordic Pulp Paper Res. J. 8 (1): 113-199.

Penniman, J.G. 1992. Comparison of pulp pad streaming potential measurement and mobility measurement. Tappi J. 75 (8): 111-115.

Revil, A., Schwaeger, H., Cathles, L.M. and Manhardt, P.D. 1999. Streaming potential in porous media. 2. Theory and application to geothermal systems. J. Geophys. Res. 104 (B9): 20,033-20,048.

Rojas, O.J., Claesson, P. M., Muller, D., and Neauman, R.D. 1998. The effect of salt concentration on adsorption of low-charge-density polyelectrolytes and interactions between polyelectrolyte-coated surfaces. J. Colloid Interface Sci. 205: 77-88.

Rzenhak, R., Kienle, D., Kawakatsu, T., and Zimmermann, W. 1999. Partial draining of a tethered polymer in flow. Europhys. Lett. 46 (6): 821-826.

Sanders, N.D. and Schaeffer, J.H. 1995. Comparing papermaking wet-end chargemeasuring techniques in kraft and groundwood systems. Tappi J. 78 (11): 142-150.

Scallan, A.M. 1989. The electrical conductance of pulp suspensions. Tappi J. 72 (11): 157-162.

Schlesinger, R., Roder, T., Gotzinger, G., Sixta, H., Harasek, A., and Friedl, A. 2005. Influence of hemicellulose aggregate and gel layer formation on flux and retention during nanofiltration of alkaline solutions. Desalination 175 (1): 121-134.

Stone, J.E. and Scallan, A.M. 1966. Influence of drying on the pore structures of the cell wall, in Consolidation of the Paper Web (R. Bolam, Ed.) Vol. 1, British Paper \& Board Makers Assoc., p. 145.

Stone, J.E. and Scallan, A.M. 1968. A structural model of the cell wall of water-swollen wood pulp fibers based on their accessibility to macromolecules. Cellulose Chem. Technol. 2 (3): 321-342.

Strazdins, E. 1972. Factors affecting the electrokinetic properties of cellulose fibers. Tappi 22 (12): 1691-1695.

Tatsumi, D. and Yamauchi, T. 1997. Depth profile of paper additives within a pulp fiber. in The Fundamentals of Papermaking Materials, Baker, C.F. (Editor), Pira International, Leatherhead, UK, pp. 789-814.

van de Steeg, H.G.M., Cohen Stuart, M.A., de Keiser, A., and Bijsterbosch, B.H. 1992. Polyelectrolyte adsorption: A subtle balance of forces. Langmuir 8: 2538-2546.

van de Ven, T.G.M. 1999. Effect of fiber conductivity on zeta potential measurements of pulp fibers. J. Pulp Paper Sci. 25 (7): 243-245.

Wågberg, L. 2000. Polyelectrolyte adsorption onto cellulose fibers - A review. Nordic Pulp Paper Res. J. 15 (5): 586-597.

Wågberg, L., Ödberg, L., Lindström, T., and Aksberg, R. 1988. Kinetics of adsorption and ion-exchange reactions during adsorption of cationic polyelectrolytes onto cellulosic fibers. J. Colloid Interface Sci. 123 (1), 287-295.

Wan, Q.-H. 1997. Effect of electrical double-layer overlap on the electroosmotic flow in packed-capillary columns. Anal. Chem. 69 (3): 361-363.

Wang, F. and Hubbe, M A. 2001. Development and evaluation of an automated streaming potential measurement device. Colloids Surf. A 194 (1-3): 221-232. 
Wang, F. and Hubbe, M.A. 2002. Charge properties of fibers in the paper mill environment. 1. Effect of electrical conductivity. J. Pulp Paper Science 28 (10): 347353. 


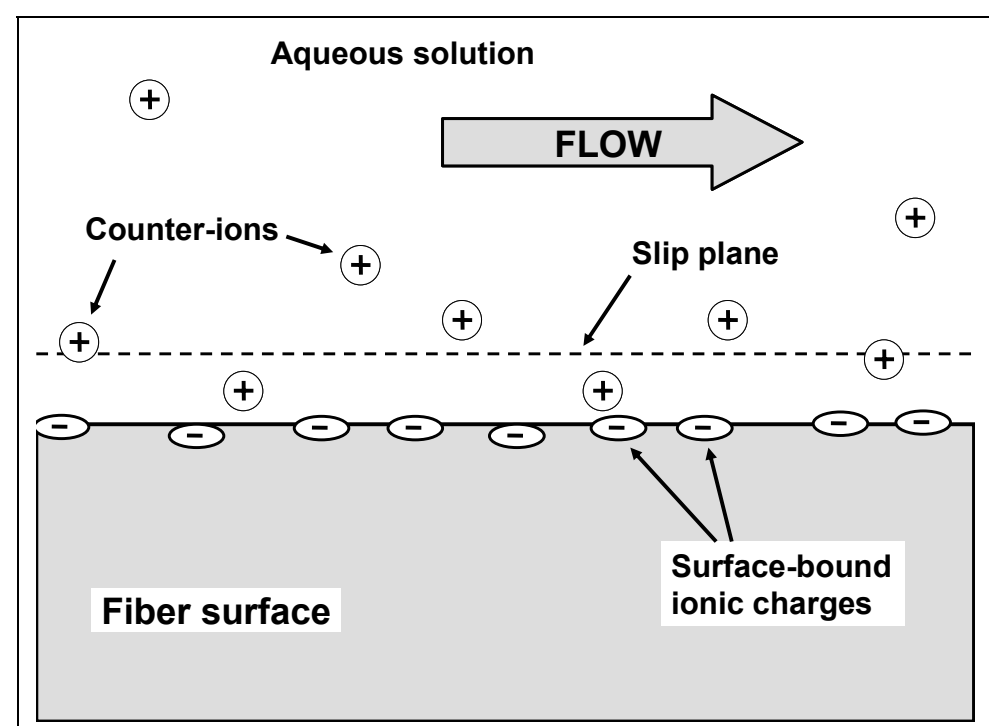

Fig. 1. Idealized explanation of streaming potential of porous substrate

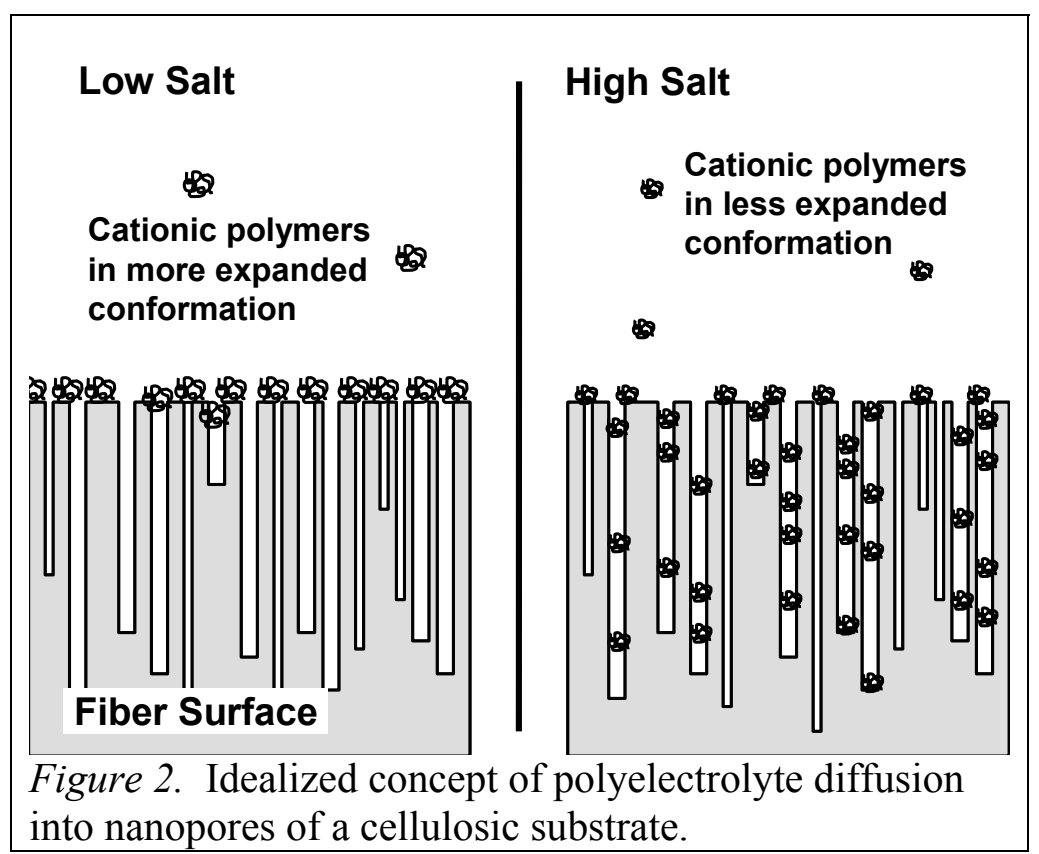



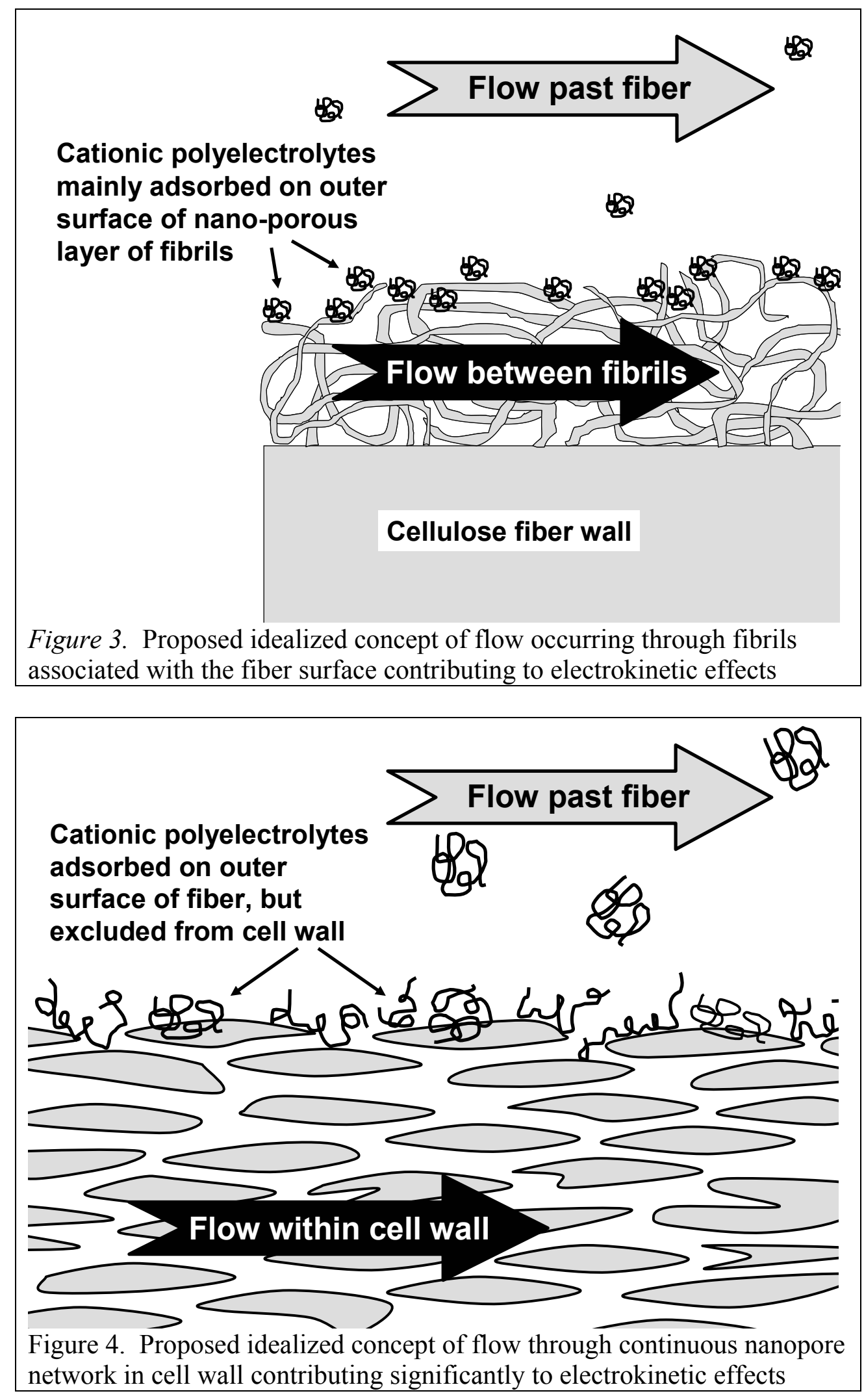

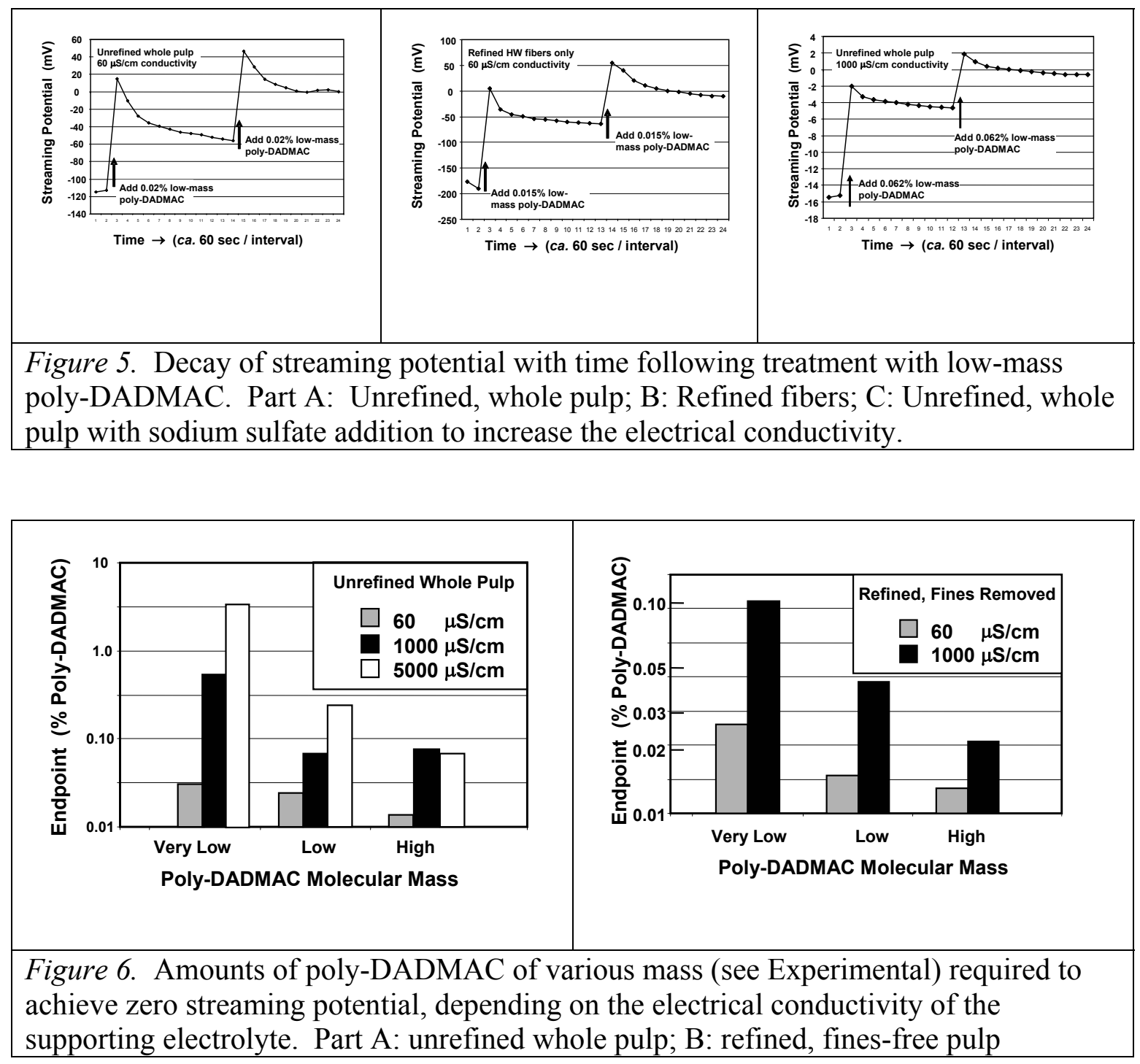


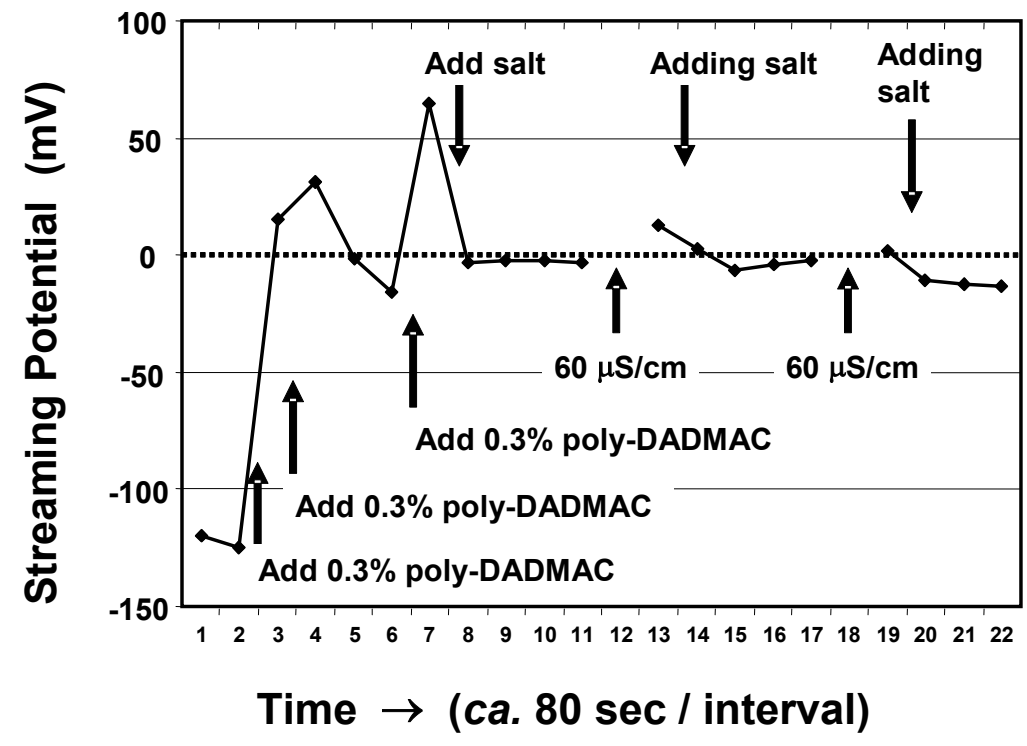

Figure 7. Streaming potentials resulting from addition of polyDADMAC, the passage of time, and from cycling between 60 $\mu \mathrm{S} / \mathrm{cm}$ and $1000 \mu \mathrm{S} / \mathrm{cm}$ conductivity

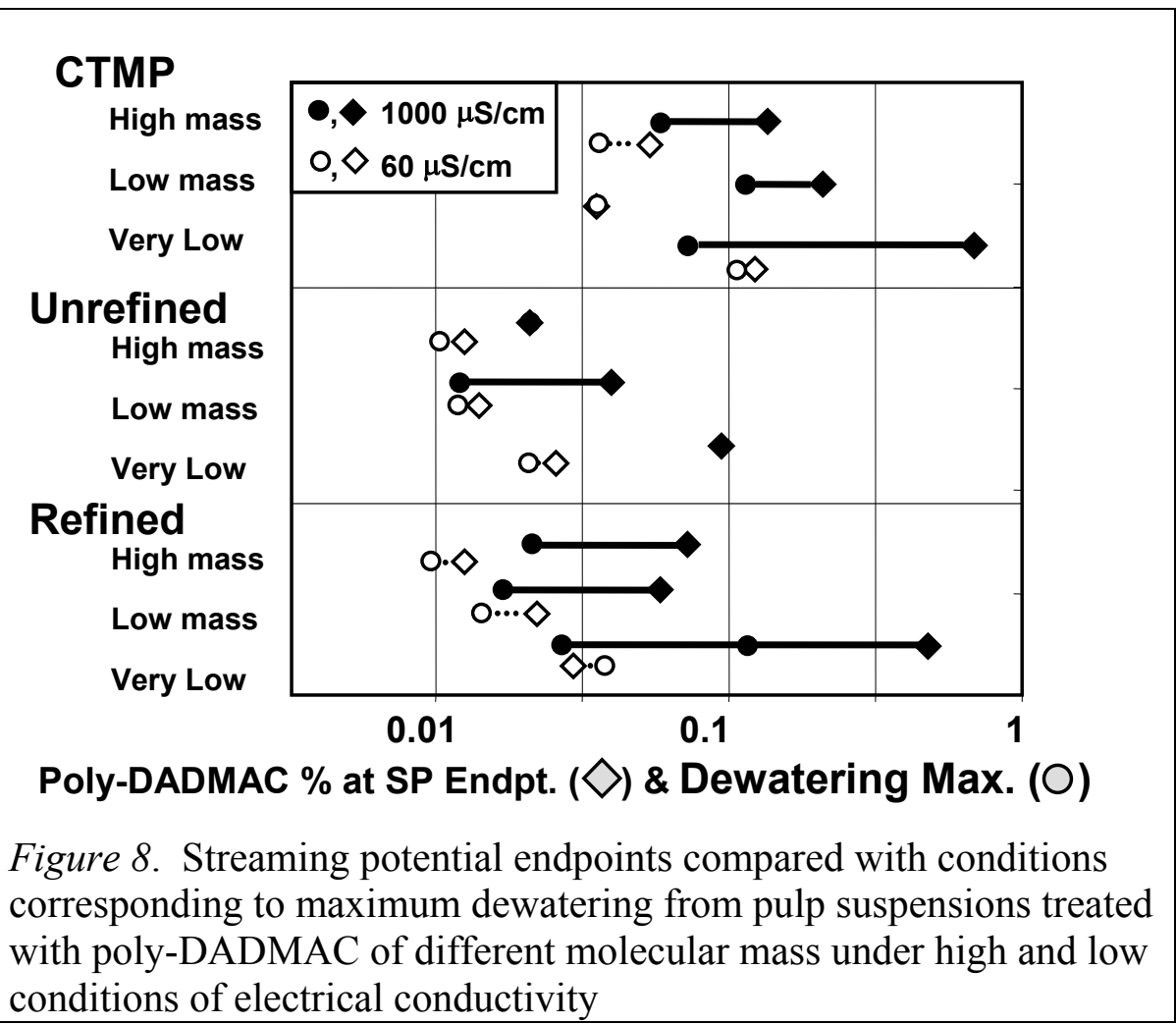



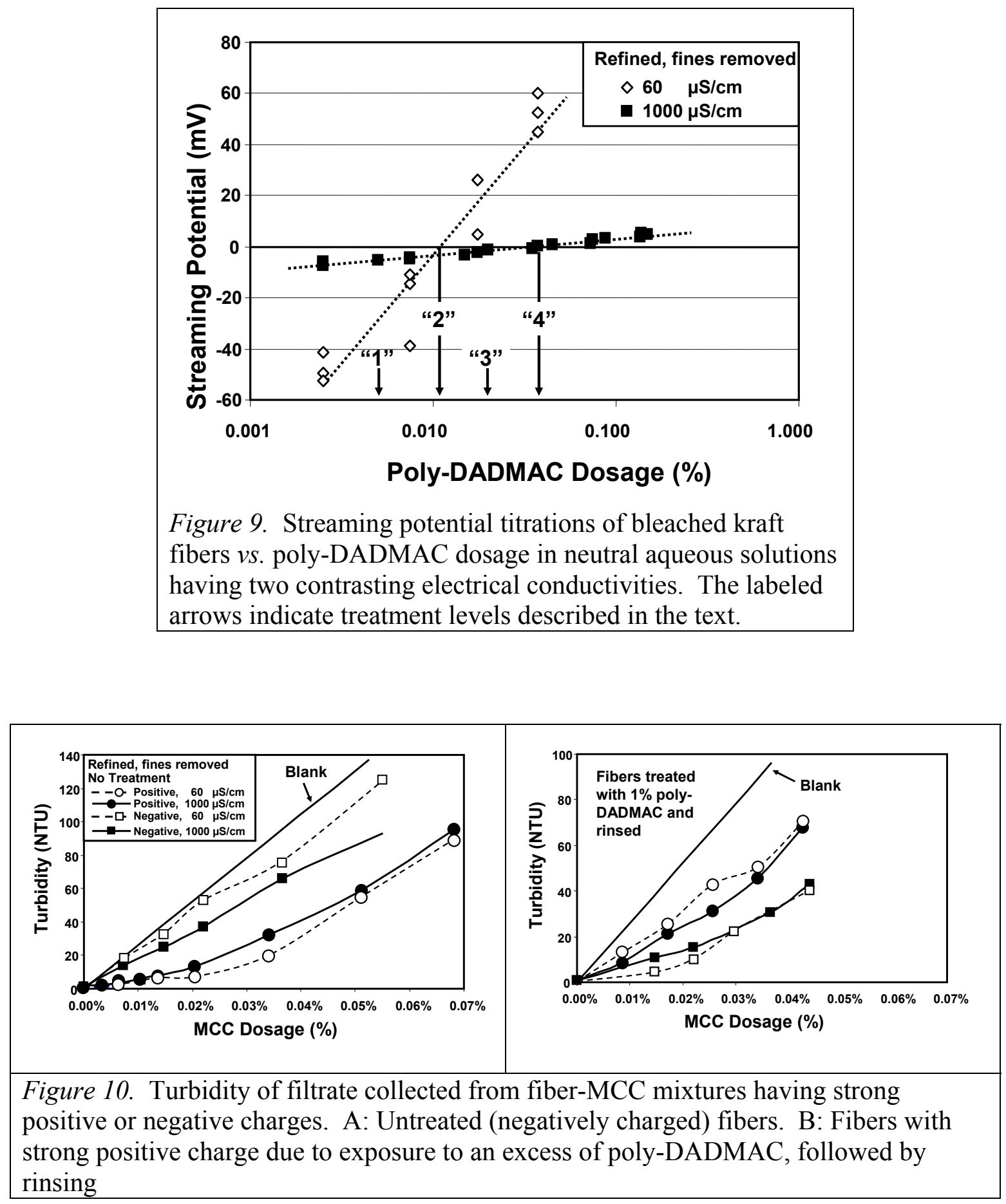


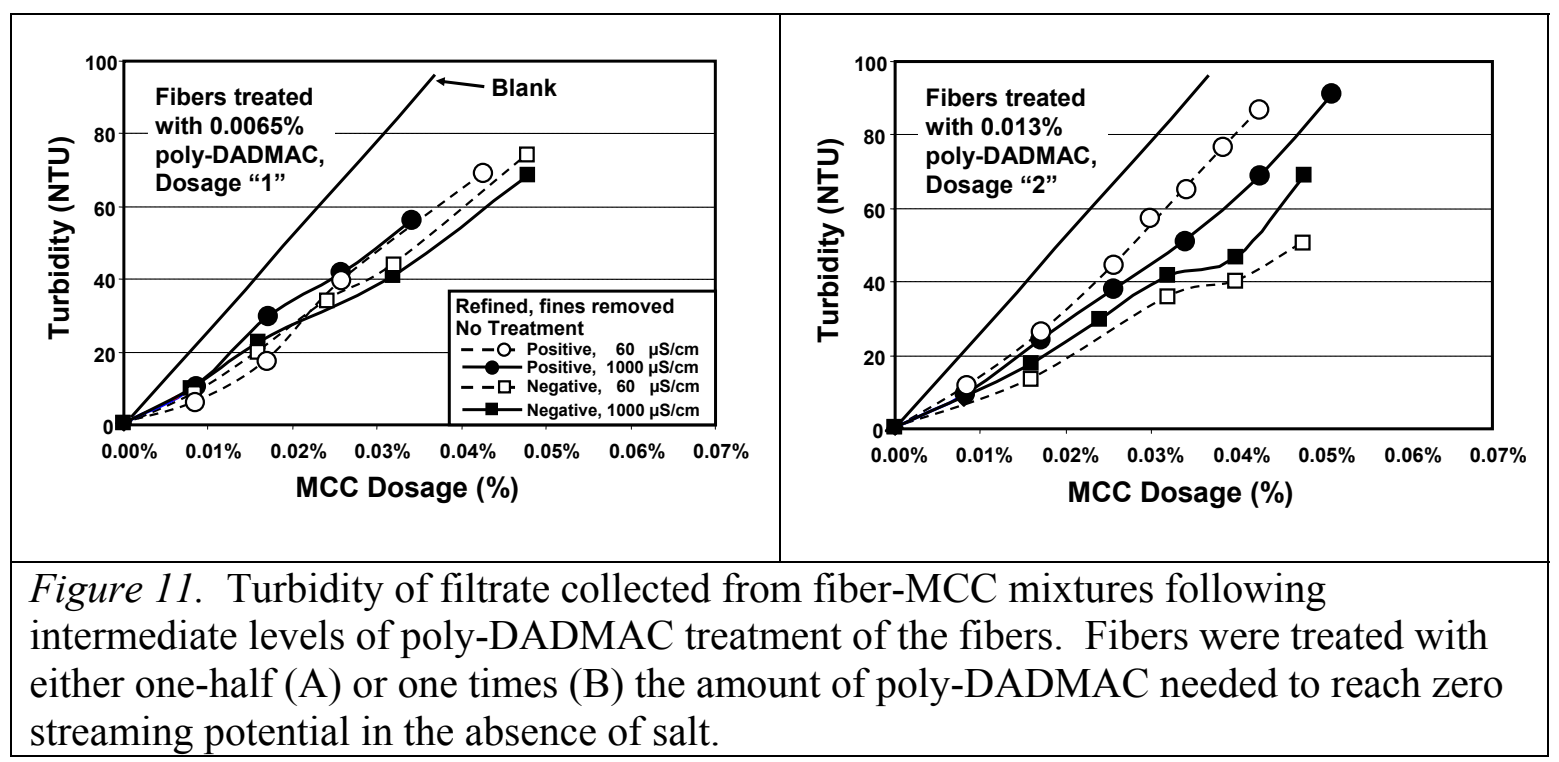

